\title{
Conspiración del silencio en el proceso de muerte, el opio de la conciencia \\ El arte de existir con la conciencia
}

\author{
Mikel García García ${ }^{1}$.
}

Resumen

El artículo presenta reflexiones del autor, basadas en su experiencia clínica, como investigador y personal, sobre el morir y la atención al muriente. Se denuncia la situación general de muerte indigna a lo largo de algunas décadas en las que sólo cambian las formas. Se profundiza en el uso de los analgésicos, la morfina. Se apuntan modos de transformar la realidad actual y se concluye con una hipótesis de corte junguiano.

Palabras clave: Muerte. Morfina. Sí-mismo. Jung. Conciencia. Muriente

\section{Contenido}

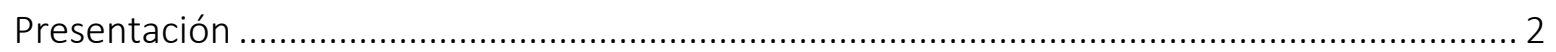

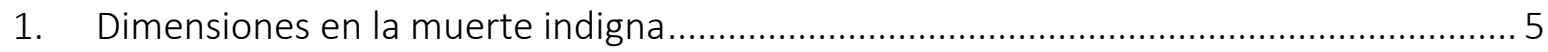

1.1. Evolución de estas dimensiones a lo largo de los años......................................... 7

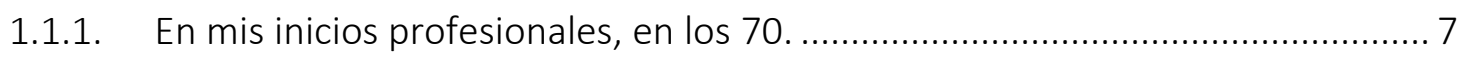

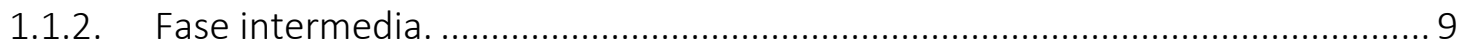

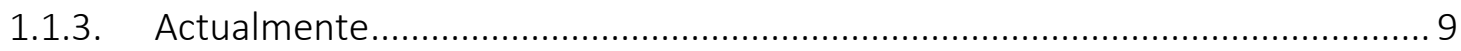

2. Transformar lo actual. Imaginar la muerte. Trabajo personal, social y político ............ 13

2.1. Duelos y sacrificios para crecer. Un antiguo cuento africano: Mujer Celestial ...... 14

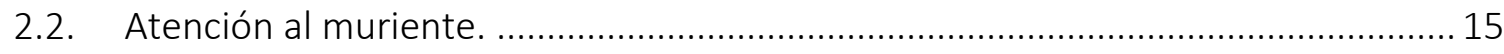

2.2.1. "Fábula-mito Cuidado" de Higinio (Gaius Julios Hyginus) .............................. 15

2.2.2. El acompañamiento es un arte de alianza. ................................................... 16

Aportaciones junguianas. Hipótesis propuesta ................................................................ 19

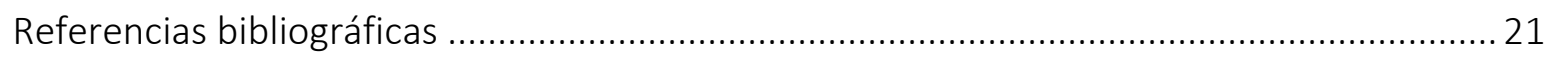

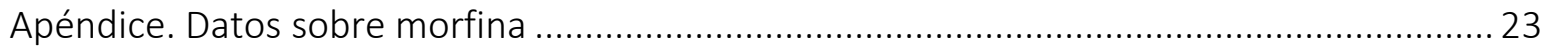

\footnotetext{
${ }^{1}$ Médico. Psicólogo. Psicoanalista Junguiano. iratxomik@gmail.com WEB Personal WEB profesional
} 


\section{Presentación}

A lo largo de la historia, la muerte ha estado presente en el pensamiento humano, ya sea como acontecimiento individual, social, religioso, o político (Eccles, 1992; EvansPritchard, 1973; Morin, 1951).

En 42 años de práctica clínica primero como médico rural, y más adelante como psicoterapeuta he acompañado a morir a bastantes personas tanto pacientes como allegados. Cuando una muerte es digna y cuando no lo es, se reconoce por lo que se siente tanto en el proceso de muerte como por las consecuencias en el duelo de los vivos. Es un proceso de aprendizaje en el que se va entendiendo de qué factores depende una u otra forma de morir. Mucho de lo que acontece alrededor de la muerte resulta un misterio incognoscible al principio, pero con cada experiencia, sobre todo porque te transforma, se van comprendiendo más cosas. He explicado algo sobre ello en el apartado Mi experiencia profesional de "Integración de la muerte. Pulsación de vida"2 (García, 2015)

En tantos años ha cambiado mucho la atención al muriente, pero, después que he sido informado de algunas experiencias recientes de muertes, y leído informes recientes de trabajos sobre experiencias en unidades de cuidados paliativos, dudo de que se esté realmente avanzando hacia morir con dignidad. De ahí mi motivación en reflexionar, revisar lo que ocurre y compartir mis reflexiones.

Lo primero compartir preguntas que nos podemos hacer tan paradójicas como la física cuántica que las inspira: Si todo el universo está hecho de los mismos materiales, ¿eso significa que todo el universo está muerto? o ¿que todo el universo está vivo? ¿Se trata sólo de una cuestión de complejidad? ¿Significa eso que nunca moriremos porque nunca estuvimos vivos? ¿Son la vida y la muerte una cuestión irrelevante y no nos habíamos dado cuenta? ¿Es posible que seamos más parte del universo de lo que pensábamos?

El "morir con dignidad" ha sido un referente que he tenido presente desde el inicio de mi práctica y desde un tiempo está en el debate ético del final de la vida humana como "derecho a morir con dignidad" cobrando bastante peso en la actualidad. El debate hace emerger la necesidad de reflexionar sobre que es la dignidad humana, especialmente en relación con el sufrimiento y la muerte, reflexión que pone, además, en tensión la concepción interna y social del sentido de la vida humana.

La "muerte digna", requiere tanto un abordaje integral del muriente, en sus diferentes dimensiones: física, psicológica, social, y espiritual, como el considerar el acto de morir como un "acto humano". Pues ante la inevitabilidad de la muerte cabe un ejercicio de libertad, sobre el modo de morir, lo que requiere, necesariamente, disponer de buena información y de capacidades cognitivas conscientes en un grado suficiente para el ejercicio de esa libertad. El arte de morir consiste en marcharse con naturalidad.

Estas consideraciones sobre la "muerte digna" tienen un potencial innovador transformador propiciando un cambio de "paradigma": desde una sociedad que anhela una medicina dominada por el "imperativo tecnológico", hacia una medicina humanizada; desde una ética dominada por hacer sólo lo que se ha prescrito como bueno a una ética postconvencional.

${ }^{2}$ https://ibiltarinekya.com/project/integracion-de-la-muerte-pulsacion-de-vida/ 
Los sujetos que abogan por el derecho a una "muerte digna", consideran que esta solo es posible si se acepta el derecho de cada sujeto a disponer de la propia vida, lo que le otorga y confiere el poder de demandar la eutanasia o el suicidio médicamente asistido, dado el respeto que merece la libertad y autonomía del sujeto en esa fase final de su vida. El argumento es que nadie tendría derecho a imponer la obligación de seguir viviendo a una persona que, en razón de un sufrimiento subjetivo extremo, ya no lo desea.

Llamamos eutanasia a una actuación cuyo objetivo es causar la muerte a un ser humano para evitarle indignidad. Es una forma de homicidio, pues implica que un humano da muerte a otro, sea mediante un acto directo, sea mediante la omisión de la atención y cuidados. Suicidio asistido es la acción de una persona para acabar con su vida, que cuenta con la ayuda de alguien que le proporciona los conocimientos y los medios para hacerlo.

Este escenario de "muerte digna" puede hacer que el profesional, que se ocupa de un paciente dependiente del sistema sanitario, se enfrente al dilema sobre si respondería positivamente o no ante la petición de eutanasia (E) o suicidio asistido (SA), siendo estos "actos de respeto a la voluntad del sufriente" y "de compasión” por quien los ejecuta.

Quien asiste a personas en el final de la vida está condicionado tanto por la cultura que le ha modelado como por la formación recibida en las universidades. Las convicciones morales y religiosas condicionan, más que los conocimientos científicos, tanto a quien está muriendo como a quienes lo atienden, determinando qué es lo que consideran que es el comportamiento adecuado.

Como médico hice el famoso Juramento de Hipócrates, quien reclama de los médicos el compromiso de no dar a nadie una droga mortal aun cuando les sea solicitada, ni tampoco dar consejos con tal fin. En la formación médica subyace un "complejo de Asclepio" de ser capaz de vencer la muerte. El hijo de Apolo, antecesor de Hipócrates fue formado por el centauro Quirón en las artes de curación, pero recibió de Atenea un cuenco con sangre de la Gorgona que tenía poder de resucitar a los muertos. Zeus mató a Asclepio con un rayo cuando resucitó a Hipólito. Zeus no estaba conforme con la resurrección de los mortales pues temía que se complicase el orden del mundo ya que Hades y otros protestaban.

Las leyes consideran delito todas estas modalidades citadas de E y SA. Los pacientes no lo expresan, aunque lo deseen, los sanitarios dispuestos no exploran, no escuchan porque no hay salida legal ya que realizarla podría suponer acusaciones penales.

Sin embargo, aunque no se habla la demanda está latente y la frustración de los pacientes es también un desgaste y un sufrimiento. Para un médico conocer las razones por las que una persona solicita la eutanasia o la asistencia al suicidio, podría ser un estímulo para desarrollar estrategias adecuadas de cuidados. Además, algunos pacientes hablan a pesar de todas las constricciones del contexto, en mi experiencia sobre todo los más ancianos.

Para la tradición cristiana, el significado que se atribuye al concepto "morir con dignidad" se distingue radicalmente del propuesto por los defensores de la eutanasia. Esta tradición rechaza recurrir a la eutanasia y al suicidio asistido. Lo que se entiende por "derecho a una muerte digna" es el derecho a vivir humanamente la propia muerte. Esta tradición incluye lo divino en lo humano, y, precisamente Cristo es un referente para el proceso de morir. Al principio de mi praxis era frecuente que los creyentes aceptaran un sufrimiento que les acercase al de la pasión de Cristo, sintiéndose culpables si no lo hacían, incluso algunos esperaban que ese sufrimiento les redimiese de culpas y lo que facilitaba estar más preparados para el cielo. La iglesia propiciaba esta posición. En ese escenario el ofrecimiento de analgésicos no era aceptado. 
Para el ser humano muriente, morir con dignidad requiere varias dimensiones que estén operando en lo social: -Atención al moribundo con todos los medios que posee actualmente la ciencia de la salud: médica, psicológica; -Aceptar el Morir en cuanto "acción personal" que debe ejercer el paciente con su libertad; -Liberar a la muerte del "ocultamiento" a que es sometida en la sociedad actual; -Organizar los servicios sanitarios con el fin de que la muerte sea un acontecimiento asumido y vivido en clave comunitaria; -Favorecer, en la muerte, la experiencia de la dimensión religiosa en su función de religare.

La espiritualidad se puede definir en base a tres aspectos primordiales: significado y propósito; la voluntad de vivir; y la fe en uno, en los demás o en Dios. De todos ellos la religión se ocupa de una parte, aunque llega a imponerse del conjunto, hasta tal punto que es común no entender que la espiritualidad es una dimensión humana que orienta el desarrollo de la conciencia y es independiente de las creencias.

Quien muere en un hospital está en un sistema de personas que tienen visiones distintas de lo que significa morir con dignidad. Puede que distintas a la suya. Los equipos tienen a conformarse a la opinión mayoritaria, en el caso sanitario al "imperativo tecnológico" (Hans, 1979) que conduce a una "obstinación terapéutica" o "ensañamiento terapéutico". Es decir, actuando bajo el imperativo ético de considerar que "es éticamente exigible todo lo que es técnicamente posible" se implementan medios que retardan artificialmente el momento de la muerte con el fin de evitar toda duda de un posible subtratamiento. El ensañamiento terapéutico es una consecuencia del complejo de Asclepio

Zylicz, médico holandés, describe las razones más habituales por las que los enfermos piden que se les ayude a acelerar su muerte. A: Afraid (miedo) B: Burn-out (desgaste emocional) C: Control of Death (deseo de controlar la muerte) D: Depression (depresión) E: Excrutiating pain (dolor insoportable).

El deseo de controlar la muerte es una de las defensas para evitar la ansiedad y el miedo a la muerte, que es tan frecuente en nuestra cultura, que habitualmente se mantiene una "vigilancia inconsciente" (Holbrook, Sousa, \& Hahn-Holbrook, 2011) en "el campo ultramarginal de la consciencia", para detectar alarmas que pongan en riesgo la identidad, y cuando algún estímulo interno o externo, puede hace aflorar "la muerte" a la conciencia se activan automáticamente mecanismos de defensa para alejarlos (Greenberg, Pyszczynski, Solomon, Simon \& Breus, 1994).

Las razones citadas por Zilicz tienen interés porque informan de la realidad y hacen ver la necesidad de una atención multidisciplinar. Una respuesta favorable de eutanasia podría suponer, en algún caso, aliarse con una defensa ante la ansiedad de la muerte del paciente. La respuesta más integradora podría ir en el sentido de ayudarle primero a superar el miedo. Los pacientes murientes aceptan afrontar el abordaje de sus defensas siempre y cuando se sientan acompañados en ese trabajo.

Una razón difícil de expresar y poco recogida es el "dolor espiritual": El reconocimiento de la total falta de sentido de seguir estando vivo por considerar que la vida carece de la calidad mínima para que merezca el calificativo de digna, con el sufrimiento que conlleva.

Cicely Saunders, fundadora del St Christopher's Hospice en 1967, precursora del movimiento Hospice que acabaría inspirando el término "cuidados paliativos", definió el concepto de "Dolor total" que relaciona el grado de percepción y las dimensiones del dolor de los pacientes, además de con la enfermedad con la presencia de los otros síntomas, y también con la soledad, el miedo, la falta de comunicación, el grado de ajuste emocional y 
de adaptación a la enfermedad y la dimensión espiritual (capacidad de búsqueda de sentido en la vida).

Para algunos pacientes las creencias religiosas funcionan como protectoras de la ansiedad ante la muerte. Creer en otra vida, ubica el morir como un rito de paso hacia otra existencia, un corte temporal, y a la muerte como algo vencible e ilusorio. No hace falta hacer un duelo, una despedida definitiva, solo un adiós, nos veremos en un futuro, y en la medida de lo posible seguiré cuidando de ti desde el otro lado, y mejor que antes pues seré más perfecto. Y se suele esperar que les vengan a ayudar en el tránsito. Algunos fenómenos del estado no ordinario de conciencia alrededor de la muerte se interpretan como que efectivamente ya está cerca la muerte porque los familiares muertos del muriente se sienten presentes e incluso aparecen en visiones o imágenes oníricas. Hay estudios que hacen énfasis en esta función protectora de la religión y consideran que la creencia fortalece la resiliencia ya que los sujetos afrontan el proceso de morir con más calma, serenidad...

Se suele expresar que mejor es morir sin enterarte, eso es el deseo de una muerte dulce. Es un deseo negador del dolor del proceso de la muerte y de la etapa posmortem. Los fenómenos de experiencias cercanas a la muerte evidencian que una salida fácil y rápida de la vida no sirve, pues tras la muerte uno vive lo que se tiene que vivir en ese estado, y, puede experimentar tener que enfrentarse a sus propios monstruos en soledad. Desde una posición mecanicista estas experiencias de muerte cercana EMC se entienden como ilusiones por la afectación neurológica, y en su polo opuesto, místico, se toman como pruebas científicas que validan la existencia de vida tras la muerte tras la muerte.

Alrededor de la muerte muchas personas experimentan fenómenos no ordinarios de conciencia, los que encajan en las expectativas sociales se comunican y pueden tener la función de dulcificar la muerte otros fenómenos más extraños, o que contrastan con lo conocido se ocultan por la perplejidad o miedo que producen.

El trabajo para la muerte digna requiere extenderse más allá del momento de la muerte, necesita incorporar la etapa post mortem a la etapa previa a la muerte. En la etapa pre mortem el sujeto hace, en compañía, parte del trabajo de morir, separándose del mundo, de las relaciones, del cuerpo, se va preparando para la siguiente etapa para el trabajo que va a hacer en soledad. La muerte requiere que el sujeto haga el ejercicio de elaborar varios "duelos" que el yo debe hacer secuencialmente en el conjunto de las fases.

\section{Dimensiones en la muerte indigna}

Me parece útil proponer considerar cuatro fenómenos que en mayor o menor grado se producen alrededor de la muerte indigna habitual en nuestras sociedades, pues, la realidad es que, en la actualidad, muchas personas no mueren en paz. Se muere como se vive. Las personas, que vuelven, y relata haber experimentado EMC cuentan que el estado posmortem tras la muerte clínica ha sido duro.

1.- La "conspiración del silencio". Se oculta la información veraz al muriente. En la conspiración entran sanitarios, familia y muriente. Este tampoco quiere saberla (Fase de negación de Kubler Ross (1975). Los sanitarios no abordan dar malas noticias. Esta conspiración atenta a la veracidad, a la libertad, al beneficio del paciente, a su autonomía y a la justicia.

2.- La "desproporcionalidad terapéutica". Platón o Aristóteles enfatizaban lo inadecuados que resultan aquellos esfuerzos médicos que sólo lograrán prolongar los sufrimientos. El juicio acerca de la proporcionalidad de una determinada intervención médica 
debe hacerse con referencia al beneficio global de la terapia y no sólo en relación a los posibles efectos fisiológicos que ella sea capaz de inducir. Un aspecto relevante es que se medicaliza en exceso cuando se podrían implementar técnicas psicológicas.

3.- La "no prevención". No solo no se cuida la previsibilidad cosa que es función del sanitario, funcionando sobre la marcha, detrás de los acontecimientos. Lo más grave es que no se informa adecuadamente de las consecuencias de los tratamientos y las formas de paliarlas.

3.- El "abandono". La no atención suficiente. La falta de seguimiento continuo. Y en grados mayores el rechazo. Evadir el trato de calidad con el muriente, que frecuentemente genera una sensación de impotencia, reforzada por la herida narcisista de no poder vencer a la muerte. En el profesional fracasa el aspecto salvífico de su acción grabado a fuego en su formación y el éxito de su trabajo.

Es sencillo entender que a más "conspiración del silencio" más de las otras dimensiones y que todas se interrelacionan retroalimentándose.

¿De qué depende?

La atención de pacientes moribundos confronta a los familiares, sanitarios y sociedad, con la mala tolerancia habitual para enfrentar el sufrimiento y la muerte.

El acompañamiento a pacientes moribundos nos confronta, así, con nuestro trabajo de aceptar la finitud propia de la condición humana y pone a prueba la verdad de nuestro respeto por la dignidad de toda persona, aun en condiciones de extrema debilidad y dependencia, tarea que no siempre resulta sencilla.

La muerte humana es un fenómeno social, aunque para cada sujeto sea individual e intransferible; lo frecuente es que sea experimentada con ansiedad frente a la muerte propia, según una configuración que depende de la personalidad, desarrollándose una serie de mecanismos defensivos contra la posible emergencia de dicha ansiedad. La Teoría de Gestión del Terror ha aportado mucho conocimiento en este terrero; es patrimonio del "estado" quien hace las valoraciones sobre qué muertes son legítimas y cuáles no. Tabú. Secuestro de la muerte.

En definitiva, existe bastante miedo a la vida (y a la libertad), lo que imposibilita integrar el yo con el todo, y, consecuentemente miedo a la muerte, que impide integrar el ser y el no-ser. Spinoza afirma: "El hombre libre en nada piensa menos que en la muerte, y su sabiduría es una meditación no sobre la muerte, sino sobre la vida". Spinoza en Ethica, Proposición LXVII (1987).

Las defensas más profundas de la muerte, las distales, más alejadas de la conciencia, son cosmovisiones sociales, cuya función es generar una sensación simbólica de inmortalidad, lo que es una negación profunda de la muerte (Florian \& Mikulincer, 1998). Creencias religiosas, identidades nacionales... Las defensas profundas mejoran la autoestima (Greenberg, et al., 1986; Greenberg, et al., 1994). Los bajos niveles de autoestima aumentan el nivel de ansiedad a la muerte (Abeyta, Juhl \& Routledge, 2014). Los sujetos y colectivos amenazados responden aferrándose con fuerza a tradiciones culturales, y con disposición al uso de la violencia para defender lo propio frente al extraño, en una suerte de fanatismo (Routledge, Juhl, \& Vess, 2013). Se aumenta el nivel de fanatismo defensivo ante la incertidumbre de la muerte Hogg (2007). Cuando se enfrentan a la incertidumbre, los individuos apoyan a grupos que son percibidos como más capaces de actuar con poder (Hogg et al. , 2007) de salvarlos, dando explicaciones que reduzcan la incertidumbre. 


\subsection{Evolución de estas dimensiones a lo largo de los años.}

\subsubsection{En mis inicios profesionales, en los 70 .}

La "conspiración del silencio" era tremenda, estaba justificada por un convencimiento de que la verdad hunde al sujeto y lo que le impide poner en marcha recursos. Esta infantilización del paciente ubicaba al profesional en un lugar desde el que ejercía un paternalismo, el uso de analgésicos era limitado, se retrasaba su indicación (en parte influían mitos sobre la morfina y la lacra de conocer la cantidad de morfinómanos que había entre profesionales), el paciente estaba abandonado a su suerte, en un estado confusional.

No en todos los lugares ni por todos los profesionales. En mi experiencia rural podría hablar de un contexto distinto más cercano a la muerte digna. Con una "conspiración del silencio" parcial. Fue frecuente que los pacientes hablasen sin cortapisas conmigo, pero existiese entre nosotros una alianza en la que no estaban otros: familiares, sociedad, incluso párroco. Es frecuente que los murientes sepan los límites de sus familiares y decidan ocultarles la verdad, existen varias razones. Una frecuente es que los murientes no quieran hacerse cargo del derrumbe que los familiares puedan experimentar al saber la verdad, bastante tienen con su trabajo. En bastantes casos los vivos no dejen a los murientes abandonarse a su muerte, por dolor, por culpa, por sentirse abandonados...

En el 89 realicé un estudio sobre actitud ante la muerte en Navarra. Entre ellos una muestra de 48 médicos de Atención Primaria. Muchos médicos han elegido su profesión para curar y salvar vidas venciendo a la muerte, y quizá también, como dice Nuland, para sobreponerse al temor que a ellos mismos les causa saber que van a morir como parece desprenderse de estudios que muestran que la carrera de medicina atrae a las personas más angustiadas por la muerte.

¿Se puede decir que los médicos por su profesión están más preparados para hablar de la muerte?

Se presentan datos de la cantidad de experiencia que dicen tener en relación a la muerte, y de un test en el que puntúan la importancia que tienen 40 actitudes propias en su relación con los murientes. Las respuestas a las 40 actitudes se han estudiado en un análisis factorial que los agrupa en 12 factores, que engloban varias actitudes. En el gráfico se ve la distribución de los 12 factores entre ambos géneros, ordenados según la importancia que ese factor tiene en el estudio.

Se observa que ambos géneros tienen diferencias en casi todos los factores, en algunos muy grandes, la mayor similitud es el 1 pro, que es el que menos importancia tiene en el conjunto.

En la tabla se citan las actitudes que están en varios de los factores: 9,4,11 y 1 .

El 1, último e igual en ambos géneros, es el que contiene las actitudes más favorables a una relación eficaz con el paciente: Estar seguro, ser perseverante y paciente, experto, cooperativo, dispuesto a ayudar sin estar ansioso.

Los hombres puntúan más en el factor 9 (Estar concentrados, sin ser consecuentes ni cuidadosos) y 11 (estar activos y vivaces), las mujeres más en el 4 (estar interesadas, atentas, haciendo preguntas, pero sin ser claras ni sinceras).

Lo más concluyente es que el género marca diferencias claras, los hombres están menos en la relación que las mujeres, pero estas aun estando no pueden ser claras y sinceras. La actitud más favorable es igual en ambos géneros, pero es la última. 
Este estudio fue importante para detectar la necesidad de formación y para implementar programas.

Cantidad experiencia con muerte

\begin{tabular}{lcc}
\hline & Frecuencia & Porcentaje \\
\hline Poca & 10 & 20,8 \\
Moderada & 33 & 68,8 \\
Mucha & 5 & 10,4 \\
Total & 48 & 100,0 \\
\hline
\end{tabular}

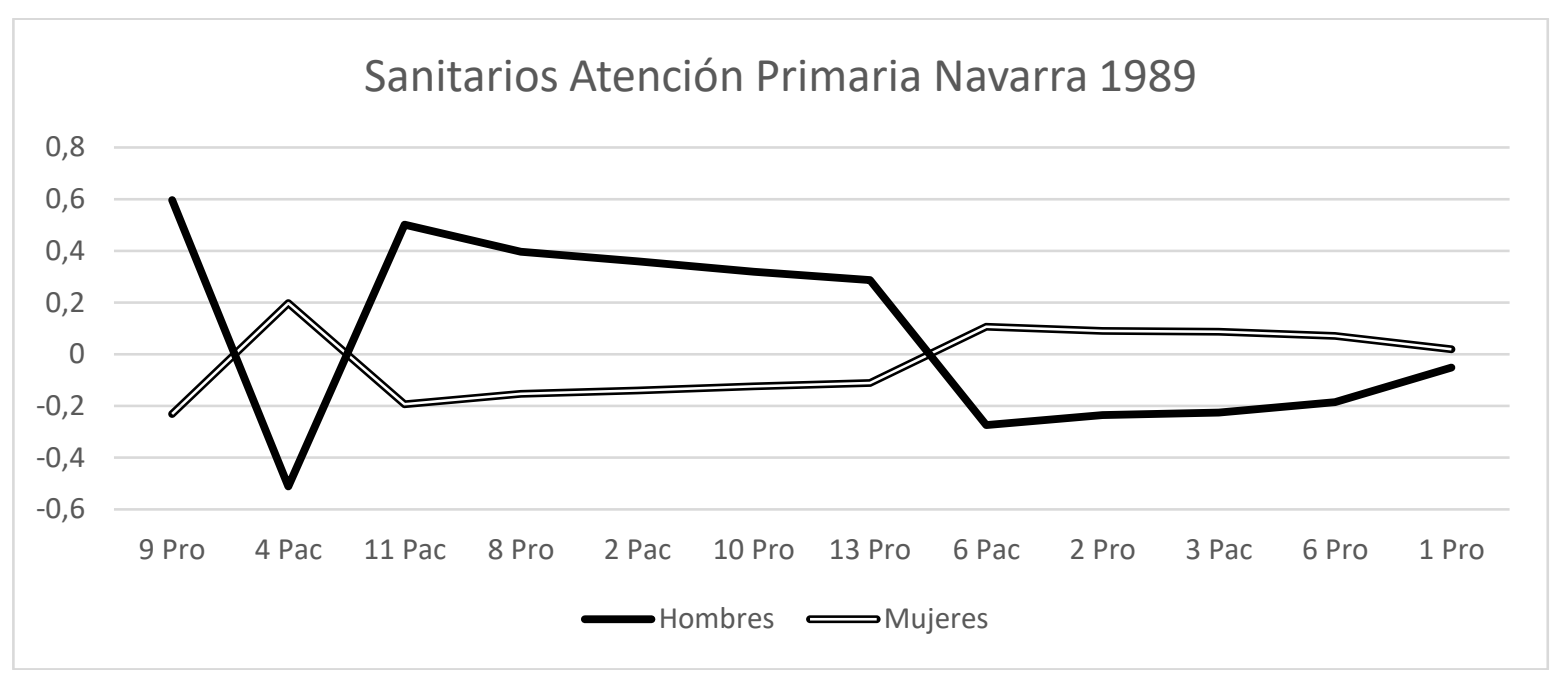

\begin{tabular}{|c|c|c|c|c|c|c|c|}
\hline 9 & \multicolumn{3}{|c|}{4} & 11 & \multicolumn{3}{|c|}{1} \\
\hline Consecuente & $-0,313$ & Interesado & 0,341 & Activo & 0,390 & Seguro & 0,776 \\
\hline Concentrado & 0,422 & Atento & 0,353 & Vivaz & 0,311 & Paciente & 0,764 \\
\hline Cuidadoso & $-0,310$ & $\begin{array}{l}\text { Haces o harías } \\
\text { Preguntas }\end{array}$ & 0,370 & & & $\begin{array}{l}\text { Dispuesto a } \\
\text { ayudar }\end{array}$ & 0,561 \\
\hline & & Claro & $-0,480$ & & & Experto & 0,575 \\
\hline & & Sincera & $-0,709$ & & & Perseverante & 0,535 \\
\hline & & & & & & Ansioso & $-0,514$ \\
\hline & & & & & & Cooperativo & 0,482 \\
\hline
\end{tabular}




\subsubsection{Fase intermedia.}

Llegaron los estudios que demostraban que saber la verdad era más eficaz para la respuesta del paciente. Y entonces se interiorizaron como un protocolo: Se pasó a decir la verdad de golpe sin preparación del paciente ni del terreno y sin seguimiento del impacto.

Los frenos culturales y religiosos a los analgésicos fueron remitiendo lo que permitió su uso de un modo más científico.

La morfina (ver notas históricas) ${ }^{i}$ apareció a principios del siglo XIX. Es un analgésico que se obtiene de la planta del opio (Papaver Somniferum), conocida popularmente como adormidera que en esta época se recetaba como analgésico. Por sus virtudes somníferas, en honor al dios del sueño Morfeo, se denominó con el nombre de morfina. Los opiáceos se unen a los receptores de opiáceos (que se encuentran en muchas partes del cuerpo, cerebro, médula espinal, tubo digestivo), lo que reduce la transmisión de mensajes de dolor al cerebro, y se reduce el dolor. No tratan la causa subyacente del dolor. Los opiáceos se utilizan para tratar un dolor moderado a intenso que no se trata correctamente con otros analgésicos.

La morfina, además de su efecto analgésico, tiene el efecto sedante (Morfeo) y, como estupefaciente, produce euforia en dosis iniciales y bajas. Cambia el estado de ánimo no solo por el bienestar de quitar el dolor disfórico, sino por el efecto directo euforizante.

\subsubsection{Actualmente}

Predomina el convencimiento de la necesidad de los cuidados paliativos (CP). Y las legislaciones sobre eutanasia la van liberando de efectos penales y regulando su uso.

En Holanda, en algunos informes se recoge que $15 \%$ de los fallecidos muere por eutanasia. El $56 \%$ de los pacientes que solicitan eutanasia activa es por por un sentimiento de pérdida de dignidad y $47 \%$ abogando por tener un dolor intratable.

En opinión de los médicos tratantes en el $17 \%$ de las solicitudes de eutanasia aún había alternativas terapéuticas paliativas que ofrecer a los pacientes, pero éstos las rechazaron. La razón más importante que tuvo el $35 \%$ de los médicos para rechazar solicitudes de eutanasia fue su opinión personal de que el sufrimiento del paciente no era intolerable.

En CP la eficiencia ya no consiste en curar sino en cuidar, porque cuando ya no hay más nada curativo para hacer, hay que dejar de hacer y cambiar de objetivos para que el paciente muera bien. Por eso su objetivo radica en llegar a tiempo y lograr para el paciente y para la familia, la calma en la aceptación de la realidad de la muerte. Permitir morir, cuidando y evitando el sufrimiento evitable. El desarrollo de programas de cuidados paliativos (CP) intenta facilitar la disponibilidad de opioides y el mejorar la formación específica de los profesionales.

Un indicador del acceso al alivio del dolor de las personas en un país es el consumo de morfina per cápita/año. La JIFE (Junta Internacional de Fiscalización de Estupefacientes) en 2007 reveló que 7 países de ingresos altos (EE.UU., Francia, Canadá, Alemania, Austria, Reino Unido y Australia) consumieron el $84 \%$ de la cantidad de morfina para uso médico en el mundo, pero tienen menos del $10 \%$ de la población mundial.

El consumo de sustancias opioides, se ha casi duplicado en los últimos años en España, según datos de la Agencia Española de Medicamentos y Productos Farmacéuticos. Mientras en el 2008 se consumían 7,25 dosis diarias por cada mil habitantes, en el 2015, la utilización extrahospitalaria de opioides alcanzó las 13,31 dosis. La prescripción médica del 
potente fentanilo creció un $65 \%$ entre el 2008 y el 2015. "No estamos ni mucho menos en los niveles de abuso excesivo que han alcanzado en Estados Unidos, pero sí que recomendamos a oncólogos, traumatólogos y cirujanos, que tengan mucho cuidado con estas prescripciones", indica la doctora Lara Grau, psiquiatra especialista en Adicciones y Patologías Duales en el Hospital del Vall d'Hebrón.

¿Qué genera esté consumo?

Un aumento de los factores que generan sufrimiento y se añaden a los clásicos (vacío existencial, ignorancia, deseo insatisfecho, ...). Entre los nuevos: Uno se debe convertir en "una empresa de sí mismo", autovalorándose continuamente en un mercado competitivo que obliga a reinventarse permanentemente, siendo emprendedor, para sobrevivir. El mundo exige un riesgo heroico al individuo, y debe lograrlo sobrepasando las condiciones políticas estructurales de la inseguridad actual, cuando, en realidad, es incapaz de controlarlas: sufrimiento, falta autoestima y fracaso narcisita; la inconsistencia de las identidades líquidas, la difusión de identidad; la fragilidad de los vínculos sociales reales, sustituidos por los virtuales; el derrumbe de los referentes simbólico culturales que llenaban el vacío existencial.

No solo hay aumento de sufrimiento, sino necesidad de doparse para sobrevivir en una civilización competitiva para poder seguir el ritmo asumiendo implícitamente, aunque inconscientemente ser un esclavo moderno. Las políticas comunitarias del "bienestar" al ampliar el objeto inicial de los psicofármacos desde la población manicomial al conjunto de la población, marcaron un estilo de medicalizar el malestar para llegar a un bienestar.

El discurso neoliberal y la voracidad del mercado de consumo ha visto potencial de plusvalía, y ha contribuido a medicalizar o psicologizar todo tipo de sufrimiento psíquico, y a conseguir clientes creando la demanda con narrativas explicativas de enfermedad, y de nuevas enfermedades para los que hay tratamientos.

Se ha erradicado el valor del sufrimiento como adversidad que coloca al sujeto en un desafío para desplegar recursos creativos con la finalidad de superar la dificultad, crecer, y desarrollarse, aprendiendo de la adversidad. Proceso que realmente consolida capacidades de resiliencia.

El sufrimiento de la muerte, de los procesos de duelo, del dolor del parto, se presentan como objetivos a batir con los recursos modernos, presentados como efectivos e inocuos, que además del bienestar permiten seguir activo en lo cotidiano. En la sociedad el abuso de opiáceos va generando problemas de adicción a sustancias y dependencia del sistema.

Nacer y morir, dos procesos de separación radical de una existencia previa, en los dos se abusa de la analgesia.

Pero centrándonos en la muerte, y dado que da igual que el muriente se convierta en un morfinómano ¿El uso actual de la morfina está contribuyendo a un proceso de muerte digna?

El exceso de morfina tiene un efecto: es un opio de la conciencia. El paciente inicialmente está eufórico. La euforia tiene la vertiente interesante de vivir un bienestar, pero las funciones cognitivas (sedación) están disminuidas y el paciente puede valorar de un modo delirante la realidad que vive, minimizando lo negativo. A medida que va teniendo tolerancia y las dosis aumentan este efecto de dispercepción puede ir en aumento, con mayor nivel de confusión, vértigo, en algunos casos dolores de cabeza, pérdidas de memoria o alucinaciones. Estos síntomas negativos se pueden controlar con otros fármacos, y de nuevo el paciente, se siente bien. Tanto que incluso llega a dudar de que se vaya a morir y a pensar que igual se cura, aunque el deterioro corporal vaya en aumento. Percepción que también suelen tener los familiares. Una situación de delirio compartido. 
Si acontece la muerte se experimenta una sorpresa inesperada.

¿Y si llega el momento en que las dosis de morfina no pueden controlar el dolor?

Queda proponer la sedación terapéutica o la sedación terminal. En ambas se administran fármacos para reducir la consciencia con el fin de aliviar uno o más síntomas refractarios y con su consentimiento explícito o por representación. La paliativa puede ser intermitente, y más o menos superficial o profunda. La terminal es una disminución profunda, continuada y previsiblemente irreversible de la consciencia de una persona cuya muerte se prevé muy próxima, con la intención del alivio de un sufrimiento físico o psicológico inalcanzable con otras medidas, y con el consentimiento explícito, o por representación.

Las preguntas comprometidas son bastantes. ¿cuándo se ha llegado a esa situación, podemos contar con que la persona tenga capacidades suficientes para entender que esa sedación significa prácticamente la muerte? ¿se le da el tiempo y espacio para que se despida definitivamente de sus allegados? ¿no estamos hablando de una eutanasia pasiva? ¿no podía haberse planteado en periodo previo en el que el sujeto tenga un estado de conciencia suficiente para hacer lo que necesite antes de morir? ¿se busca activamente el efecto de la morfina como opio de la conciencia? ¿no sería preferible introducir antes la marihuana terapéutica?

Cuando el sujeto tiene unas creencias religiosas que usa como religión segurizante antídoto de la angustia de muerte "opio del pueblo", puede quizás aceptar mejor la morfina como opio de la conciencia, y la sedación terminal, como tránsito dulce al otro lado, sin que sea una eutanasia, sino un acto terapéutico, con consecuencias terminales que no son el objetivo principal sino uno secundario, aunque sea la muerte. Y si sucede al interior de la conspiración del silencio mejor pues las responsabilidades o culpas se diluyen al repartirse.

Esto puede interpretarse como resiliencia, la aceptación calmada del proceso de muerte debida a la protección de la religión.

El proceso de duelo de la muerte no cabe para el muriente y queda muy dificultado para la familia. El tránsito se inviste de un proceso de sufrimiento que debe llevarse con alegría. No basta la resignación. Tampoco es aceptable la fórmula de que «hay que resignarse a la voluntad de Dios». Subrepticiamente se ensalza el sufrir como un acompañar al sufrimiento de Cristo en la pasión, colaborando con él, sufrimiento que redime al muriente. Estos argumentos antes eran manifiestos, resultando un freno, a los analgésicos paliativos.

En la investigación que estoy realizando como doctorando en "Paz, conflictos y desarrollo" en la Universitat Jaime I de Castellón, Experiencias tempranas de violencia. Desarrollo moral y actitudes hacia la paz, tengo recogidos datos que permiten explorar la relación entre tipos de religiones y la muerte.

En la tabla siguiente se agrupan los tipos, cantidad de personas y porcentaje en la muestra. La categoría monoteísta en esta muestra es el $98 \%$ de cristianos, un 55\% de Colombia y un $45 \%$ de España.

\begin{tabular}{|c|c|c|}
\hline & Frecuencia & Porcentaje \\
\hline Monoteísta & 227 & 50,8 \\
\hline Budista & 27 & 6,0 \\
\hline Espiritualidad & 12 & 2,7 \\
\hline No creyente & 76 & 17,0 \\
\hline Agnóstico Ateo & 97 & 21,7 \\
\hline Total & 439 & 98,2 \\
\hline Perdidos & 8 & 1,8 \\
\hline Total & 447 & 100,0 \\
\hline
\end{tabular}

Mikel García García. 25 diciembre 2018 
En la tabla siguiente se presentan las puntuaciones medias de varias variables en función de los tipos de religiosidad.

"Miedo a la muerte" es un test. "Competencia personal" es una escala del test de Resiliencia. "Sentirse bien solo" es una subescala del test de resiliencia. Las dos formas de practicar la eutanasia son Subescalas del test de Competencia Moral.

Las diferencias de puntuaciones que hay en todas las escalas y Subescalas entre la categoría "monoteísta" y la "no creyente" son estadísticamente significativas mediante el análisis de Diferencia de Medias T-Student.

Esto significa que en esta muestra los monoteístas, tienen más miedo a la muerte, menos resiliencia en ambas medidas de Competencia personal y capacidad de sentirse bien solos, y se oponen a la eutanasia siento mucho mayor la oposición cuando la razón es por estar de acuerdo a su conciencia que cuando es por no atender el deseo del paciente que lo solicita.

\begin{tabular}{|c|c|c|c|c|c|}
\hline & Monoteísta & Budista & Espiritualidad & No creyente & $\begin{array}{l}\text { Agnóstico } \\
\text { Ateo }\end{array}$ \\
\hline & Media & Media & Media & Media & Media \\
\hline Miedo a la muerte & 11,361 & 12,593 & 10,833 & 10,151 & 10,701 \\
\hline Competencia personal & 5,451 & 5,369 & 6,114 & 5,915 & 5,474 \\
\hline Sentirse bien solo & 5,659 & 5,814 & 6,105 & 6,084 & 5,580 \\
\hline $\begin{array}{l}\text { Practicaría la eutanasia de acuerdo } \\
\text { a su conciencia }\end{array}$ & 1,221 & 0,852 & 1,250 & 2,368 & 1,443 \\
\hline $\begin{array}{l}\text { Practicaría la eutanasia atendiendo } \\
\text { el deseo del paciente. }\end{array}$ & 0,863 & $-0,407$ & 0,667 & 1,342 & 0,485 \\
\hline
\end{tabular}

Se han explorado estos 12 tipos de representación de muerte en un test de la investigación:

Alegre farsante; Figura Macabra; Afable Consoladora; Autómata; Vacía; Figura Amorosa; Figura acogedora; Figura específica; sabia; maestra; compañera vida; experimentada

En la siguiente tabla aparecen los resultados de 3 formas de representarse la muerte que tienen diferencias significativas entre las categorías de creencias religiosas.

\begin{tabular}{|c|c|c|c|c|c|c|}
\hline & Monoteísta & Budista & Espiritualidad & $\begin{array}{c}\text { No } \\
\text { creyente }\end{array}$ & $\begin{array}{l}\text { Agnóstico } \\
\text { Ateo }\end{array}$ & $\begin{array}{l}\text { Chi- } \\
\text { cuadrado }\end{array}$ \\
\hline Muerte alegre farsante & $34,9 \%$ & $0,0 \%$ & $2,3 \%$ & $18,6 \%$ & $44,2 \%$ &, $008^{*}$ \\
\hline $\begin{array}{l}\text { Muerte Afable } \\
\text { Consoladora }\end{array}$ & $41,6 \%$ & $7,9 \%$ & $5,6 \%$ & $30,3 \%$ & $14,6 \%$ & ,020* \\
\hline Muerte Autómata & $40,0 \%$ & $0,0 \%$ & $3,1 \%$ & $36,9 \%$ & $20,0 \%$ & $.009^{*}$ \\
\hline
\end{tabular}

*El estadístico de chi-cuadrado es significativo en el nivel, 05 . 
Los monoteístas se representan la muerte de modo significativo como "Afable consoladora" y como "Autónoma”, mientras que los Agnósticos Ateos lo hacen como "alegre farsante"

La acepción Afable consoladora, podría estar relacionada con la esperanza maternal de ser un tránsito dulce, quizás facilitado por figuras acompañantes de familiares que les esperan o como alguno ha escrito en la personificación de la muerte la misma virgen María. La acepción de autónoma le confiere frialdad, distancia, cumple su función, puede ser vencida.

En la siguiente tabla se presentan las medias en Asco a la muerte y Pensamiento Mágico, siendo mayor en monoteístas respecto a No creyentes, aunque solo esta diferencia es significativa en Pensamiento Mágico ( $\mathrm{Sig}=, 030$ para $\mathrm{p}<, 005)$.

\begin{tabular}{llcc}
\hline \multirow{2}{*}{ Religion } & \multicolumn{2}{c}{$\begin{array}{c}\text { Pensamiento } \\
\text { Mágico }\end{array}$} & Asco Muerte \\
\cline { 3 - 4 } & & Media & Media \\
\cline { 3 - 4 } & Monoteísta & 4,258 & 6,591 \\
& No creyente & 3,289 & 6,156 \\
\hline
\end{tabular}

Podría decirse que las creencias no les protegen a los monoteístas del miedo a la muerte, aunque las creencias sí que les aporten un significado que la hace más soportable imaginando serán acompañados y consolados, con una conciencia mágica, en la convicción de que no tienen que elaborar un final.

Los budistas presentan más miedo a la muerte y son más deontologistas que los monoteístas. La muestra es bastante más pequeña y estos resultados poco sólidos. Pero tiene sentido. Para los budistas la muerte representa un estado de bastante trabajo. En el bardo posmortem esperan experimentar un estado confuso en el que las ilusiones les pueden despistar de seguir su camino hacia una nueva reencarnación. Los budistas se preparan para la muerte ya que son conscientes de la importancia de ese estado, cuyo trabajo empieza tras la muerte clínica. Los médicos tibetanos de la muerte se especializan en ese acompañamiento posmortem.

Estos datos anticipan como podrían llegar al momento de la muerte. Son sujetos que aún no están en el proceso y cabe la posibilidad de que cuando les toque se movilicen otros recursos y cambien, pero en la experiencia clínica sabemos que es más probable que la reacción inicial sea la de incrementar las defensas.

\section{Transformar lo actual. Imaginar la muerte. Trabajo personal, social y político}

Es posible desarrollar la habilidad de mantener una relación con la muerte que sirva para mejorar la vida, como propone Platón, quien afirma en su diálogo Phaedon, que "la filosofía es una meditación de la muerte" (Cooper, 1997). Imaginarla, personificarla, dialogar con la imagen para aceptar su enseñanza como límite que enseña a vivir integrando el no-ser.

"Ciertamente la muerte es una terrible brutalidad - no hay que dejarse engañar acerca de eso- no sólo como acontecimiento físico, sino mucho más aún como psíquico: un ser humano es alejado de nosotros y lo que permanece es el glacial silencio de la muerte. Ya no existe más esperanza de relación alguna, pues 
todos los accesos se han roto. Hombres a los que se desearía una larga vida desaparecen a mitad de su vida y hombres inútiles alcanzan una avanzada edad. Esto es una cruel realidad que no debe paliarse. La brutalidad y arbitrariedad de la muerte puede amargar a los hombres hasta el punto de que concluyan que no existe dios misericordioso alguno ni justicia ni bondad” Jung "Recuerdos, sueños, pensamientos" (Jung, 1998a, p. 368).

Prevención. Preparación para la muerte. Desarrollar la capacidad de ir resolviendo los duelos de pérdida de estados que necesitan evolucionar para desarrollarse.

La realidad realmente importante para el humano tiene la estructura de un acontecimiento, no la de un contenido objetivo, y puede expresarse únicamente, como diría Aristóteles, en una práxeos mímesis, en la representación de una acción, es decir, en una "historia".

Recuerdo que al explicar a una madre la muerte de su hijo por SIDA le citaba argumentos científicos. Ella no entendía. Tenía que aceptar la muerte, por una enfermedad rara, nueva y que generaba mucha incertidumbre. Me di cuenta que le tenía que contar una historia. Cuando le dije que los virus eran un ejército que lanzaba flechas que mataban las células defensivas de su hijo, lo entendió. Necesitaba primero entender el SIDA como un sujeto que actuaba con una intención. Después ya entendió lo científico

Cada sujeto construye un relato mítico de su historia biográfica. Ayuda a descubrirlo el conocer, descubrir, leer otras historias míticas que presentan conflictos existenciales similares a los que cada uno tiene que vivir.

\subsection{Duelos y sacrificios para crecer. Un antiguo cuento africano: Mujer Celestial}

Un padre que advierte a su joven hijo que la mujer celestial vendrá una noche y querrá acostarse a su lado. El padre describe la belleza y el poder de seducción de esta visión celestial, y le dice que amanecerá muerto si accede al ofrecimiento de la mujer celestial. El padre parece cada vez más preocupado por el riesgo que corre su hijo (quizá conoció a la mujer celestial cuando era más joven) y decide trasladarse a otro pueblo para que ella no pueda encontrar al joven. Pero en ausencia de los padres, una noche llega la mujer celestial y le dice al hijo que quiere acostarse a su lado. A pesar de todas las advertencias, el hijo queda tan impresionado por la belleza de la doncella que acepta dejarla acostarse a su lado durante la noche. Pero a la mañana siguiente el hijo está muerto, y la mujer celestial se horroriza porque no era su intención causarle ningún daño. Va a ver enseguida a un viejo chamán que vive por allí y le pide ayuda. Viene el chamán y, al cabo de un tiempo, enciende una gran hoguera y echa una lagartija en la parte más ardiente. Dice que le devolverá la vida la persona que ame tanto al joven muerto como para atreverse a entrar en la hoguera. Lo intenta la mujer celestial, pero fracasa; la madre del joven fracasa también, al igual que su padre. El fuego quema mucho. Entonces viene una joven sencilla del pueblo que amaba al joven en secreto; entra en la hoguera y rescata la lagartija. Su amor humano, común y corriente tiene la facultad de salvar al joven. El muchacho despierta. Se realiza un festejo para celebrarlo al que acuden todos los protagonistas.

En medio de los festejos, el viejo chamán comunica al pueblo que hay que tomar una decisión más. Vuelve a encender la hoguera, echa la lagartija en medio de las llamas y le dice al joven que tiene que tomar una decisión. Si rescata la lagartija del fuego (y ahora tiene 
poder para hacerlo), la joven vivirá y su madre morirá. Pero si deja la lagartija en el fuego, entonces morirá la joven y vivirá su madre.

\subsection{Atención al muriente.}

Basada en dimensiones opuesta a las que propician la muerte indigna: alianza en la búsqueda dela verdad, intervenciones proporcionadas; previsibilidad y prevención de los efectos interventores; atención continuada, seguimiento.

"La verdad más bella no sirve de nada si no se ha convertido en la experiencia más intima del individuo. Toda respuesta unívoca, 'clara', permanece estancada en el cerebro y penetra sólo en casos muy raros hasta el corazón. No nos urge 'saber' la verdad, sino 'experimentarla'." (Carl G. Jung).

Los cuidados paliativos $\mathrm{CP}$ son un avance. Aún falta mucho para desarrollar su potencial. Pero se quedan cortos. Lo mismo que evolucionaros desde Hospice, podrían evolucionar hacia otra terminología. El término paliativo denota acomodación a lo irreversible de la mejor forma posible.

En el período muriente se puede crecer y desarrollar la conciencia por eso algo como "Cuidados para morir con dignidad" podía ser más adecuado.

La siguiente fábula tiene interés para el cambio conceptual en el tipo de cuidado.

\subsection{1. "Fábula-mito Cuidado" de Higinio (Gaius Julios Hyginus) ${ }^{3}$}

"Un día cuando se disponía a atravesar un río, Cuidado se sintió inspirado al fijarse en un pedazo de barro. Entonces maravillado comenzó a darle forma, cuando apareció Júpiter. Cuidado pidió a Júpiter que le soplara con su espíritu, lo que éste hizo de buen agrado. Cuidado quiso nombrar a su criatura, pero Júpiter se lo prohibió, a menos que le llamara como él. Esto suscitó una discusión entre Cuidado y Júpiter, el padre de los dioses. En eso apareció Tierra, quien también quiso llamar a la criatura con su nombre pues ésta estaba hecha de su propia materia. Ahora eran tres los envueltos en una discusión, de manera que pidieron a Saturno que actuara como árbitro. Este tomó la siguiente decisión que pareció justa:" Usted, Júpiter quien le otorgó el espíritu, recibirá de vuelta este espíritu cuando la criatura muera. Usted, Tierra quien le otorgó el cuerpo, recibirá de vuelta la corporeidad de la criatura cuando esta muera. Más usted, Cuidado, quien moldeó a la criatura, determinará cuales son los cuidados que debe recibir la criatura mientras ésta viva.". Una vez más comenzaron a discutir sobre el nombre de la criatura, cuando Saturno decidió que sería llamada hombre que se deriva de "humus" que quiere decir tierra fértil."

En el modo de ser de Cuidado la centralidad para el pensamiento es el pathos o sentimiento.

\footnotetext{
${ }^{3}$ Higinio en su obra "Fabulae seu Genealogiae", traducido como "Genealogía de la fábula" recopila historias y mitos de la tradición griega y latina (contiene 300 leyendas, historia y mitos). Aquí se encuentra el mito-fábula sobre Cuidado y su creación del primer ser humano, así que podemos categorizarlo como un mito de creación. El mito-fábula de Cuidado constituye el número 220 y es de origen griego.
} 
Los humanos nos sentimos ligados los unos con los otros, sin los otros no somos, en un todo orgánico diverso e incluyente. Un útero cósmico: Una fuente que une, sustenta y energiza, con carácter de misterio. Ese misterio es un atractor no atemoriza, sino que fascina.

Cuidado revela la dimensión de lo femenino en lo humano: hombre y mujer. Lo femenino se consolidó en la historia a partir del neolítico cuando las culturas vivían en comunión con la naturaleza. Eran sociedades matrilineales con un profundo sentido de lo sagrado de la vida y la tierra. Esto fijó en la humanidad una memoria permanente en el inconsciente colectivo que se manifiesta a través de símbolos, sueños y arquetipos.

La evolución histórica ha supuesto una hegemonía creciente del patriarcado, que reprime lo femenino, lo relega a un segundo orden. La aportación del pensamiento analítico instrumental (logos) abriría el camino para el raciocinio cordial o espíritu de delicadeza siempre y cuando se haga sin la represión de lo femenino.

El demiurgo patriarcal usurpa poder y función al útero cósmico, con el soplo de su aliento crea la vida, concentra en él todo el poder de nombrar haciendo de toda la creación una posesión privada.

Los nuevos cuidados requieren una integración de lo femenino relegado. En el estudio citado del 89, el dato de las mujeres médicas que podían relacionarse, pero sin poder ser claras ni sinceras, puede ser una señal del drama de estar atrapadas en el modelo patriarcal imperante.

\subsubsection{El acompañamiento es un arte de alianza.}

La relación de demanda de ayuda, aunque sea para una eutanasia, requiere una respuesta de alianza con las partes más sanas del sujeto demandante para promover la participación transformadora.

La alianza requiere por parte del terapeuta estar activo hacia abrir la escucha, anticipar las necesidades para orientar al sujeto hacia el contacto con las mismas, y que pueda expresarlas.

Va más allá de un derecho del paciente pues es una relación de ética, aunque hay que despenalizar, "El alivio del dolor es un objetivo en común de la medicina y los derechos humanos, y el alivio del dolor y el sufrimiento de los enfermos en etapa terminal es un derecho humano que requiere atenderlo de un modo creativo, no mecánico".

Encontrar un equilibrio. Trabajar los miedos, el desgaste emocional, ... puede conducir a que el dolor espiritual sea más intenso y se convierta en la razón final de petición de eutanasia o suicidio asistido.

Las creencias, además de merecer profundo respeto, en sí mismas no son analizables. Lo que es analizable es el uso que el sujeto hace de las creencias como modo de resistirse a hacer el trabajo del duelo en la muerte. El espacio privilegiado de la religión es la gestión de las condiciones para acceder a la otra vida. En muchas ocasiones esto dificulta el realizar un duelo adecuado tanto para quien muere como para quienes le sobreviven. Si el muerto o muerta era un cuidador maternal, la creencia de la continuidad de la vida en una dimensión poderosa, como es estar en el cielo, puede hacer que el vivo siga esperando ser cuidado por el muerto y de una forma incluso más eficaz que antes.

Sin embargo, las mismas defensas pueden convertirse en aliados para una trasformación hacia la muerte digna. La convicción del más allá puede motivar que muriente y vivo acepten la separación sintiéndola temporal. Aceptar que el muerto ya está en el cielo ocupándose de su situación sin hacerse cargo del sujeto que ha quedado vivo y que el vivo 
continúa sin tutelaje y rehace su vida. Poniendo la motivación para la separación en la esperanza de un rencuentro futuro en el que podrán tener la curiosidad de conocer como les ha ido solos, a cada uno en sus respectivos viajes de vida o evolución en planos muy distintos. Ese trabajo suele ser bastante útil.

En el momento de la muerte el sujeto puede hacerse cargo de sus decisiones morales e ir más allá de las creencias convencionales.

Hace muchos años, en mi etapa de médico rural A. un anciano de 88 años estaba muriendo en casa por un cáncer de pulmón. Ya le administraba morfina en dosis bajas. Me dijo si no se podía hacer nada más. Le contesté, sin entenderle, y con extrañeza por lo que me preguntaba, que haría lo que fuera necesario. Me dijo, sí, pero me refiero a lo mismo que yo hago con mis animales cuando ya no tiene sentido que vivan, les pego un tiro y acabo con su agonía y sufrimiento. Entonces entendí. Me parecía extraño lo que pedía siendo cristiano. Le contesté señalando sobre si se daba cuenta que lo que pedía no lo permitía su religión y que eso le podía perjudicar, vamos, ir al infierno. No estaba seguro de porqué se lo decía por frenar una petición que me ponía en un aprieto, porque necesitaba sentir si su demanda era firme o podía dar bandazos. Me contestó: "He sido bueno toda mi vida y sé que por morir así Dios no me va a rechazar. Es amoroso y me recibirá. Pero quiero que esto quede entre tú y yo. No se lo digas a mi mujer, ni a mis hijos ni al cura. No lo entenderían o se opondrían". Tuve la constatación de que sabía bien lo que quería y me daba una lección de vida yendo más allá de lo que yo podía pensar antes de ser testigo de su manejo de la situación.

Era un hombre vasco, y en su cultura el animismo era el sustrato profundo de la religiosidad, aunque la religión era la católica. Fue la primera vez que me demandaron eutanasia. Una enseñanza de vida que me forjó y abrió a salir de prejuicios morales y científicos. Aprendí mucho.

Bastante más adelante entendí que el sí-mismo de A. inició un movimiento a la caza de un sujeto, presumiblemente receptivo, que pudiera actuar realizando una acción que daba sentido a la muerte de A. como el paso final de su vida digna. Un empuje a una totalidad. Muchos pacientes callan pues no encuentran contextos propicios.

Llega un momento en el que los murientes sienten que es verdad que se mueren. En algunos casos pareciera que todo lo anterior no era realmente para morir, incluso aunque estaban haciendo un trabajo para ello. Mejoras del estado general vividas con euforia son, de golpe, anuladas y la facticidad de la realidad de la muerte se impone en la conciencia. A veces he tenido que hacer un trabajo intenso y prolongado porque la cantidad de informaciones y el material que aflora es enorme y variado cualitativamente, emociones, recuerdos, fantasías, materiales oníricos fragmentados, casi todo relacionado presentado de forma caótica. Las asociaciones que se producen cada vez que se aborda un material son ricas e interconectan las informaciones, entre lo actual, la infancia, lo inacabado. Se está inmerso en un estado no ordinario de conciencia en el que diversos estados de la conciencia se presentan de forma simultánea. El haber tenido una EMC me facilita tener la calma porque sé que ese período caótico acaba en un orden que de sentido a la experiencia. Ayuda el haber navegado en esas interfaces y poder anticipar cosas que van a pasar. La ocasión más intensa duró 90 minutos, a partir de los cuales la muriente llegó a calmar sus preocupaciones y aceptar la muerte. En mi experiencia estos procesos suceden porque el muriente lo necesita, no lo "elije" conscientemente, ocurre si hay acompañantes preparados cercanos. Se tiene la sensación de que ocurre cuando están disponibles estos, cuando llegan de visita. 
Un muriente que intuía que sus acompañantes en el trance provenían del interior de su psique sin ser espíritus objetivos se sentía perplejo, no quería comunicarlo. La escucha activa propicia que se comuniquen muchas cosas y se ayude a situarlas.

En otras ocasiones el muriente dice que se muere, hace una señal, un gesto, puede hablar unos minutos despedirse y entra en coma. También parece que "elijen" hacerlo cuando están acompañados por alguien que no va a frenar su abandono a la muerte.

El parto es la separación de dos en los que uno no es consciente siquiera de la existencia del otro, pero lo va a conocer en un futuro. En la muerte es la separación de lo que se conoce, del Otro, siendo conscientes ambos del cese de la relación.

Aun después de muerto sigue la conciencia activa y más lúcida que cuando estaba ligada a la materia biológica del cuerpo recibiendo múltiples informaciones sensoriales. El muriente puede despertar de golpe y entender que se está muriendo, o puede no hacerlo y vivir el inicio de ese período como si fuese un sueño extraño, más lúcido de lo habitual.

La experiencia más dramática que me relataron fue la de un amigo, quien, a los minutos de morir, se levantó bruscamente desde la cintura, con los brazos hacia delante, los ojos abiertos y la mirada aterrorizada, cayendo inmediatamente y sin moverse más. La enfermera que estaba cerca, acostumbrada a movimientos corporales posmortem debidos a descargas de tensiones musculares, dijo no haber visto nunca algo similar y menos con esa expresión emocional. Sé que había muerto confuso, agarrado a creencias.

Es probable que el trabajo de revisión de la existencia que se produce de modo automático tras la muerte pueda lograr elaborar lo que no se había hecho antes.

Sin embargo, la atención al muriente debería contemplar que llegue preparado para reconocer esa etapa en la que ya va a hacer en soledad una revisión y evaluación del sentido de su existencia. Los budistas lo saben bien.

La muerte digna, además de lo que significa para el muriente, que no podemos verificar del todo pues se interrumpe la comunicación habitual, facilita los procesos de duelo de los sobrevivientes. Eso sí que es verificable.

"Hay una ignorancia ligada al desarrollo mismo de la ciencia, esta se debe a la forma en la que se organizan los conocimientos dentro de cada disciplina, incapaces de reconocer y aprehender la complejidad de lo real."

(Morin, 1990, p. 27)

Sin embargo, la comunicación aún tras la muerte clínica es posible. En muchas experiencias de muerte cercana (EMC) que describen personas que se reaniman tras la muerte clínica y en sincronías que se producen en los vivos se constatan fenómenos de comunicación que ayudan a la elaboración de los duelos.

En mi experiencia EMC, lo mismo que se recoge en otros testimonios, experimenté ciclos continuos de polaridades, multinivel, en una conciencia dialógica, de modo que se exploran aspectos profundos ocultos y se hacen conscientes, se revisa la existencia y las acciones desarrolladas en sus polos buenas-malas. Todo sucede como siguiendo una fuerza directriz que lo ordena y uno siente que crece en el conocimiento de uno mismo, lo que simultáneamente, produce un efecto de trascender los momentos concretos vividos y experimentar cambios de conciencia. En mi EMC esto me condujo a reconciliarme conmigo mismo, aceptar morir en paz. Debido al modo en que se experimenta un amor profundo al ser propio que se va descubriendo que es uno, y más allá del juicio, que sitúa en su lugar correcto aquello que ha sido bueno o malo, se siente finalmente un estado de beatitud que te permite abandonarte a la muerte con una calma y curiosidad enorme por lo que iba a pasar 
en adelante. Empezar a tener curiosidad por los fenómenos extraños que iba percibiendo, que fenomenológicamente pertenecían a un estado no ordinario de conciencia, que empezaba a experimentar y atribuir a que era un estado ordinario del otro lado de la vida que había conocido. Pero no morí. Volví y lo que experimenté lo trabajé en psicoterapia.

\section{Aportaciones junguianas. Hipótesis propuesta}

En este apartado voy a mencionar algunos aspectos que considero de interés y que me permiten formular una hipótesis que es novedosa y necesita más investigación para poder verificarla.

"En realidad, lo inconsciente colectivo no existe en sí mismo, ya que no es más que una posibilidad, concretamente esa posibilidad que hemos heredado de tiempos inmemoriales en forma de imágenes mnémicas o, en términos anatómicos, en nuestra estructura cerebral. No hay representaciones innatas, pero sí posibilidades innatas de representación que imponen determinados límites incluso a las fantasías más audaces, una especie de categorías de la actividad imaginativa o ideas a priori, cuya existencia, sin embargo, no puede ser captada sin la experiencia. (...) Cada una de estas imágenes encierra un fragmento de psicología y de destino humano." - C. G. Jung, Sobre el fenómeno del espíritu en el arte y en la ciencia, OC 15 (1999, p. § 126 y 127)

El inconsciente produce "símbolos religiosos" para unir (re-ligare), hacer un puente entre consciente e inconsciente. Cada símbolo es, en un sentido, un puente, pues cada símbolo tiene un pie en el inconsciente y un pie en el consciente. Hacer una elección implica un ejercicio de discriminación por el yo, teniendo en cuenta las posibilidades y las relaciones entre las elecciones posibles. Jung enfatiza que existe una tendencia innata a que los contenidos opuestos puedan dialogar entre ellos y engranen, en mutua influencia, lo que puede verdaderamente hacer que se trasciendan sus viejas oposiciones entre consciente e inconsciente y se "encuentre" una nueva posición adscrita al yo. A esa tendencia la denomina "función trascendente". En definitiva, es una fuerza teleológica del inconsciente colectivo, específicamente del sí-mismo, con una finalidad integrativa, para el desarrollo de la conciencia en el camino de la individuación.

Anteriormente he descrito fenómenos de EMC que describen personas incluida la mía, de la que puedo dar testimonio más exacto.

Experiencias recientes de muertes de allegados me han abierto a otra perspectiva que yo no experimenté y que lanzo como hipótesis:

tras la muerte clínica, y en un período corto para los parámetros temporales de la vida consciente, se puede hacer un trabajo impulsado por el sí-mismo que complete la individuación.

Explicación. En el momento en que el cuerpo pierde su integración funcional por la muerte, la corteza cerebral deja de inhibir el cerebro límbico, y este deja de inhibir el cerebro reptiliano (Mc Lean). La conciencia se expande, la función trascendente queda brutalmente activada y emergen los instintos arquetípicos que conducen a la individuación. Eros y logos muy activados e integrados.

“... Sin embargo, bajo otro punto de vista, la muerte aparece como un suceso alegre. Sub specie aeternitatis es una boda, un Misterium Coniunctionis. El alma 
alcanza, por así decirlo, la mitad que le falta, alcanza su plenitud. En los sarcófagos griegos se representaba el elemento alegre por medio de bailarinas, en las tumbas etruscas, por medio de banquetes. Cuando murió el famoso cabalista Rabbi Simon Ben Jochai, sus amigos dijeron que celebraba bodas. Todavía hoy existe cierta costumbre de celebrar en el día de los difuntos un picnic en los cementerios. Todo esto expresa la sensación de que la muerte es una fiesta alegre” Jung en Recuerdos, sueños, pensamientos"

Terminar sin completud es un sentimiento doloroso difícil de soportar. En mi opinión este sentimiento puede conducir a la necesidad de otras oportunidades para completar la totalidad: purgatorios, reencarnaciones, ...

El "Libro Tibetano de los Muertos" anticipa la posibilidad de que la muerte no sea solamente un momento trágico sino una oportunidad. Su título original "Bardo Thodol" quiere decir "la Gran Liberación por la Audición en el Estado Intermedio". Pertenece a la tradición budista "Nyingma". Da una descripción de la experiencia de morir, pasar por un estado intermedio y renacer. El propósito del texto es darnos instrucciones para aprovechar espiritualmente del momento de la muerte tanto para el muriente como para ayudar una persona moribunda, y para toda la vida y no solo para nuestros últimos momentos.

A veces el sentimiento genera en el muerto clínico un movimiento de volver a la vida, si su cuerpo lo permite por no estar demasiado deteriorado (como se recoge de testimonios de algunos que vuelven), o para comunicarse con los vivos como se recoge en testimonios de vivos que reciben informaciones en el sentido de terminar algo no resuelto.

La hipótesis que lanzo introduce un cambio sustancial y es la posibilidad de que se pueda terminar la individuación post mortem sin necesidad de más oportunidades. Libera de la pesadez de la rueda del Saṃsara que termina con el logro del moksha (unión con dios), en términos junguianos con el inconsciente colectivo.

La hipótesis completa un ciclo pues la activación de la función trascendente se hace ya antes de la muerte cuando esta llega por un deterioro progresivo. Los materiales arquetípicos que afloran, simbolizados en figuras humanizadas, pero numinosas, pueden ser literalizados como espíritus exteriores, ya que metonímicamente por la familiaridad y pre conocimiento que se tiene de ellas se desplazan a figuras de familiares muertos que acompañan al sujeto. Los muertos acceden a la consciencia. Los propios o del colectivo de los muertos. El muriente no siempre percibe que vienen a ayudar en el tránsito. A veces son una carga ya que necesitan entender su situación, pero hacerlo es para el muriente una parte de su trabajo de individuación, pues son sus muertos de los que debe liberarse mediante ese trabajo que s un duelo.

En el «país de los muertos» el alma experimenta una secreta vivificación y da forma a las huellas ancestrales, a los temas colectivos del inconsciente. Igual que una médium, da a los muertos posibilidad de manifestarse. Por ello, muy pronto después de la desaparición del alma aparecieron en mí los «muertos», y surgieron los «Septem Sermones ad Mortuos» Recuerdos, sueños, pensamientos (Jung, 1998b, p. 228).

Esa hipótesis extiende la posibilidad de muerte digna a un período postmortem.

En las muertes que atrapan de improviso, sin avisar, el proceso sería más brusco, pero la finalización la misma.

¿Todo sujeto puede hacerlo? Probablemente no. Las experiencias de negación de la muerte se extienden postmortem al menos en un período inicial, como también informan 
algunos que vuelven que experimentan su estado como un estado onírico sin reconocer que están muertos.

¿Tras eso hay algo más? Es un tema de creencias. La lucha entre ciencia y religión, se expresa también en la interpretación de los fenómenos no ordinarios de conciencia alrededor de la muerte. Si la ciencia habitual los reduce a ilusiones o alucinaciones por anoxia, para las personas con creencia religiosa avalan la vida tras la muerte, y se apoyan en datos científicos sobre estos fenómenos para afirmar que la muerte no existe, que es una etapa de transición a otra etapa menos limitada, ya que la existencia física es un período puntual de la existencia espiritual.

¿El sí-mismo nos prepara para la muerte? Una pregunta a desarrollar en trabajos posteriores.

\section{Referencias bibliográficas}

Abeyta, A. A., Juhl, J., \& Routledge, C. (2014). Exploring the effects of self-esteem and mortality salience on proximal and distally measured death anxiety: a further test of the dual process model of terror management. Motivation and Emotion, 38(4), 523528. https://doi.org/10.1007/s11031-014-9400-y

Eccles, J. C. (1992). Évolution du cerveau et création de la conscience. France: Fayard.

Evans-Pritchard, E. E. (1973). Antropología social. Buenos Aires: Nueva Visión.

Florian, V., \& Mikulincer, M. (1998). Symbolic immortality and the management of the terror of death: The moderating role of attachment style. Journal of Personality and Social Psychology, 74(3), 725-735.

García, M. (2015). Integración de la muerte pulsación de vida. Recuperado de https://ibiltarinekya.com/project/integracion-de-la-muerte-pulsacion-de-vida/

Greenberg, J., Pyszczynski, T., \& Solomon, S. (1986). The causes and consequences of a need for self-esteem: A terror management theory. En Public self and private self (pp. 189-212). Springer.

Greenberg, J., Pyszczynski, T., Solomon, S., Simon, L., \& Breus, M. (1994). Role of Consciousness and Accessibility of Death-Related Thoughts in Mortality Salience Effects. Journal of Personality and Social Psichology, 67(4), 627-637.

Hans, J. (1979). El principio de responsabilidad: Ensayo de una ética para la civilización ... Barcelona: Herder.

Hogg, M. A. (2007). Uncertainty-identity theory. Advances in Experimental Social Psychology (Academic, San Diego), 69-126. 
Hogg, M. A., Sherman, D. K., Dierselhuis, J., Maitner, A. T., \& Moffitt, G. (2007). Uncertainty, entitativity, and group identification. Journal Exp Soc Psychol, 43, 135-142.

Holbrook, C., Sousa, P., \& Hahn-Holbrook, J. (2011). Unconscious vigilance: Worldview defense without adaptations for terror, coalition, or uncertainty management. Journal of personality and social psychology, 101(3), 451-466.

Jung, C. G. (1998a). Recuerdos, sueños, pensamientos. Barcelona: Seix Barral.

Jung, C. G. (1998b). Recuerdos, sueños, pensamientos. Barcelona: Seix Barral.

Jung, C. G. (1999). Sobre el fenómeno del espíritu en el arte y en la ciencia (Obra completa, Vol. 15). Madrid: Trotta.

Kübler Ross, E. (1975). Sobre la muerte y los moribundos. Barcelona: Grijalbo.

Morin, E. (1951). El hombre y la muerte. Barcelona: Kairós.

Morin, E. (1990). Introducción al pensamiento complejo. Barcelona: Gedisa.

Routledge, C., Juhl, J., \& Vess, M. (2013). Mortality salience increases death-anxiety for individuals low in personal need for structure. Motivation and Emotion, 37(2), 303307. https://doi.org/10.1007/s11031-012-9313-6

Spinoza, B. (1987). Etica. Alianza Editorial. 


\section{Apéndice. Datos sobre morfina}

' Este opiáceo se comercializó por primera vez en 1817, anunciándose como un analgésico que, además, se podía emplear en el tratamiento de adicciones a ciertas sustancias, como el opio y el alcohol. Lo que resultó falso. Sin embargo, se produjo una incidencia de adictos a la morfina o morfinómanos, entre la "sociedad acomodada" de la época. Frecuente entre médicos y personas que tenían acceso a ellos... La farmacéutica Bayer promovió el uso de la heroína como una morfina que no causaba dependencia y se podía usar para curar la adicción a la morfina. Sin embargo, se descubrió que la heroína se transformaba muy rápidamente en el cuerpo en morfina que causaba mayor dependencia que la propia morfina.

La morfina es una sustancia altamente adictiva y entre los síntomas del síndrome de abstinencia figuran el dolor, la falta de sueño, las náuseas, el vómito, la diarrea, cambios rápidos del calor al frío, y fuertes antojos de comida, un cierto estado serotoninérgico. Tolerancia, se necesita tomar una droga en dosis más altas para lograr el mismo efecto deseado, como por ejemplo de euforia, o de alivio del dolor. Desarrollar una tolerancia supone un aumento de la dosis para los efectos terapéuticos.

El opio también es Ilamado lágrimas de amapola (poppy tears) porque se cosecha de una planta mediante una incisión en la fruta de la amapola inmadura, el látex líquido corre por la planta como si fueran lágrimas y su uso tiene una larga historia a lo largo de la humanidad. El cultivo fue usado para rituales durante el Periodo Neolítico, se sabe también que fue cultivado en la Mesopotamia. Los Sumerios lo refirieron como "planta del juego" y transmitieron su uso a los Babilonios quienes a su vez lo llevaron a los egipcios, mencionado en el Papiro de Ebers (1550 a.n.e)

Alrededor del año 1522, Paracelso hizo referencia a la base del opio como el elixir llamado Láudano de la palabra latina laudare que significa "elogiar" y lo describió como un potente analgésico que debía de ser usado con moderación.

A finales del siglo XVIII en la India se aumentó el interés por el uso del opio volviéndose muy popular entre los médicos y sus pacientes

La Guerra del Opio entre China y Gran Bretaña, 1839 -1842, se desencadenó por la introducción en China de opio cultivado en la India y comercializado por la compañía británica de las Indias Orientales. El opio (una droga estupefaciente) era fuente de ingresos para los británicos que equilibraba su balanza de pagos con China al compensar el gasto del té chino que Gran Bretaña importaba. El comercio del opio fue rechazado y prohibido por el gobierno chino. La Corona británica envió una flota de guerra que finalmente derrotó a China, firmándose el Tratado de Nanking, por el que China se obligaba al libre comercio del opio con Inglaterra, a través de cinco puertos (el más importante Cantón) y a ceder la isla de Hong Kong durante 150 años. La potencia imperialista británica facilitó la irrupción de otras potencias como Estados Unidos, Francia y Rusia que forzaron a China a firmar diversos "Tratados Desiguales" con el correspondiente menoscabo de su soberanía. Y para ello el consumo de opio entre los chinos (el adormecimiento del pueblo) era un arma de dominación. 
El uso de la morfina se propagó con la aguja hipodérmica de Alex y Wood en 1853, de tal modo que en la Guerra Civil Americana un gran número de soldados se volvieron adictos, a lo que se le denominó "Enfermedad del soldado".

Prejuicios sobre el uso de la morfina:

Si a un paciente de cáncer le han prescrito morfina, quiere decir que está muriéndose.

Esta observación era con frecuencia cierta sólo se le concedía el beneficio de un analgésico potente cuando está moribundo. En tales circunstancias, el uso de la morfina (generalmente por vía parenteral), parece precipitar la muerte del enfermo, ya agotado y desmoralizado.

Probablemente sigue siendo cierta en muchos países que no tiene suficientes recursos de morfina como ha quedado señalado

El paciente usará la morfina para suicidarse.

Cuando un enfermo de cáncer decide quitarse la vida, utiliza otros métodos, entre otras cosas porque no controla el producto.

Que no se haya comunicado ningún caso de alguien que haya utilizado la solución de morfina con este fin, no quiere decir que no lo hayan hecho, si ha ocurrido será secreto.

La morfina es peligrosa porque causa depresión respiratoria.

Es extremadamente raro que la morfina oral provoque una depresión respiratoria cuando se utiliza para neutralizar el dolor provocado por el cáncer. La morfina parenteral en dosis altas hay que manejarla con cuidado.

El sujeto que toma morfina es una especie de muerto que vive.

En su uso adecuado no suministrarla sitúa al sujeto a ser "una especie de muerto que vive" el dolor le impide la atención, la relación, ..., en dosis altas prolongando la vida innecesariamente podría tener sentido la idea. 